\title{
Antibacterial activity of isolated human intestinal microbiota Lactobacillus strains against methicillin resistant and susceptible Staphylococcus aureus
}

\author{
Maxton, A ${ }^{1}$, Benjamin, J. C. ${ }^{1}$, Ram, G. D. ${ }^{1 *}$, Bailey, S. B. ${ }^{1}$ and Ramteke, P. W. ${ }^{2}$ \\ ${ }^{1}$ Jacob School of Biotechnology and Bioengineering, SHIATS, Allahabad, Uttar Pradesh, India. \\ ${ }^{2}$ School of Basic Science, SHIATS, Allahabad, Uttar Pradesh, India.
}

Accepted 19 April, 2013

\begin{abstract}
In the present study, lactic acid bacteria were screened for anti-methicillin resistant activity. Isolation of lactic acid bacteria from 100 faecal samples of healthy adults was conducted using de Man-Rogosa Sharpe agar (MRS) and three Lactobacilli strains were isolated. The three isolates of human intestinal microbiota were identified on the basis of morphological and biochemical characteristics. The incidence of Lactobacillus plantarum, Lactobacillus acidophilus and Lactobacillus casei were found to be $43.47,34.78$ and $21.73 \%$ respectively. The antibacterial activity of these three isolates was determined against five strains of Staphylococcus aureus, including three methicillin resistant Staphylococcus aureus strains. Maximum inhibitory potential was seen in L. casei. Therapeutic efficacy of the lactobacilli strains was evaluated to control the re-emerging MRSA infection.
\end{abstract}

Key words: Antibacterial activity, Lactobacilli, methicillin resistant Staphylococcus aureus (MRSA).

\section{INTRODUCTION}

Healthcare-associated infections (HAI) are those infections that patients acquire while under the healthcare institution. Methicillin-resistant Staphylococcus aureus (MRSA) is the most common HAl causing agent and is resistant to certain antibiotics (oxacillin, penicillin and amoxicillin). In 1972, MRSA accounted for 2\% percentage of all $S$. aureus HAls reported to the centres for Disease Control and Prevention (CDC) in the U.S. Today, MRSA accounts for $60 \%$ of $S$. aureus infections. MRSA infections occur in wounds of the skin burns and other places where intravenous tubes enter the body. Infection also occurs in eyes, bones, heart and blood. Approximately $23 \%$ mortality rate is among patients with MRSA bacteremia (bacterial infections of bloodstream). Disease caused by MRSA can range from skin infections to food borne illness and severe infections such as endocarditis, osteomyelitis and sepsis (Lowly, 1998). The nasal carriage of $S$. aureus is common in $20-50 \%$ of the population (Cespedes et al., 2005). Intestinal carriage appears to be increasing among hospitalized patients and infants (Kluytmans et al., 1997).

Methicillin resistance in staphylococcus aureus is mediated by the mecA gene, which encodes for the penicillin-binding protein 2A (PBP2A) resulting in reduced affinity for the beta-lactam antibiotics including the penicillinase-resistant penicillin (Khadriand Alzohairy2010). The emergence of MRSA isolates with reduced susceptibility to glycopeptides has created need for new agents for the treatment of MRSA infections (Griethuysen et al., 1999). Widespread antibiotic usage exerts a selective pressure that acts as a driving force in the development of antibiotic resistance. The effectiveness of currently available antibiotics is decreasing due to the increasing number of resistant strains causing infections. MRSA is one such bacteria and it causes wide range of syndromes, from minor 
skin and soft tissue to life-threatening pneumonia and toxinoses such as toxic shock syndrome (Nawaz et al., 2008).

Lactic acid bacteria (LAB) are commonly defined as gram-positive, non-sporulating, catalase negative, aero tolerant, acid tolerant, nutritionally fastidious, strictly fermentative organisms that produce lactic acid as end product of carbohydrate metabolism (Hartnett et al., 2002). LAB are famous as friendly bacteria for human health. Most of the Lactobacillus species are normal and non-pathogenic microorganisms in human and animal intestine and are a vital part of the intestinal microbial ecosystem. Lactic acid bacteria have a number of properties which render them highly suitable for probiotic therapeutics which are of pharmaceutical interest. They play a significant physiological role in the maintenance of the ecological balance because their lactic acid production is responsible for low pH level in the tracts. In addition, they also produce other inhibitory substances such as hydrogen peroxide, bacteriocins and some organic acids. Other mechanisms proposed for their microbial antagonism are competition for nutrition, adhesion inhibition of pathogens to surfaces and stimulation of the immune system (Voravuthikunchai et al., 2006).

Lactobacilli, despite of their origin, have potential to inhibit the growth of pathogens, including problematic antibiotic resistant isolates due to their production of several antimicrobial compounds (Petrova et al., 2009). Verdenelli et al. (2009) reported that two Lactobacillus strains had an inhibitory effect on potentially pathogenic microorganisms such as Escherichia coli, Staphylococcus aureus, Candida albicans and Candida perfringens. Lactic acid bacteria (LAB) work via different mechanisms to exert an antimicrobial effect, but the cell envelope is generally the target. Studies have revealed that Lactobacillus reuteri isolated from healthy vaginal ecosystem (Voravuthikunchai et al., 2006) and Lactobacillus fermentum (Nawaz et al., 2008) have significantly inhibited methicillin resistant $S$. aureus. It has also been demonstrated that $L$. rhamnosus has the capacity to displace and kill $S$. aureus adhering to human intestine mucus by 39 to $44 \%$ (Vesterlund et al., 2006).

Methicillin resistant bacterial infections provide a tough challenge in the selection of antibiotics. Traditional use of antibiotics is worsening the problem. Although antibiotics are available for the treatment of MRSA infections, because of their numerous adverse effects and development of resistant strains, there is an urgent need to search for alternatives to synthetic antibiotics for treating MRSA infections. Studies were carried out to search for alternatives to synthetic antibiotics against MRSA. LAB demonstrates many properties which make them highly suitable for probiotic therapeutics of pharmaceutical interest. $L A B$ has become an attractive option of modern medical practice. Recently attention has been paid to their health promoting properties. Of particular importance are their probiotic properties and specially the ability to compete with pathogens.

The present study was carried out to isolate Lactobacilli and to observe its efficacy against MRSA, in controlling MRSA infections as well as providing a new strategy to treat re-emerging infections.

\section{MATERIALS AND METHODS}

\section{Test pathogen}

Five isolates of $S$. aureus were collected from Microbial Culture Collection Bank (MCCB) of the Department of Microbiology and Fermentation Technology. The $S$. aureus strains were MCCB0045, MCCB0046, MCCB0065, MCCB0066 and MCCB0067.

\section{Isolation of lactic acid bacteria}

100 human faecal samples were collected and $10^{3}$ dilutions of faecal samples were prepared in sterile normal saline, then swab inoculated on de Mann Rogosa Sharpe (MRS) agar plates. The plates were incubated anaerobically using anaerobic jar, at $37^{\circ} \mathrm{C}$ for $48 \mathrm{~h}$ to obtain colonies (De Man et al., 1960).

\section{Identification of Lactobacillus species}

The bacterial colonies on incubated plates were identified on the basis of cultural, morphological and biochemical characteristics as described in the Bergey's Manual of Determinative Bacteriology (Holt et al., 1984).

\section{Cultural characteristics}

The isolates were identified on the basis of different colony characteristics like diameter, consistency, colour, texture, elevation, margin, etc.

\section{Morphological characteristics}

The organism was subjected to Gram's staining and observed under $100 \times$ objective for observing the morphological characteristics such as the shape and arrangement (clusters or chains) of cells, and gram-reaction (gram-positive or gramnegative).

\section{Biochemical characteristics}

The following biochemical tests were performed for the identification of lactic acid bacteria.

\section{Indole test}

The test tubes containing tryptophan broth were inoculated with the test organism and incubated aerobically at $37^{\circ} \mathrm{C}$ for $24 \mathrm{~h}$. After incubation, $0.5 \mathrm{ml}$ Kovac's reagent was added gently. Red colour formed in the alcohol layer indicated positive reaction.

\section{Methyl red test}

Five drops of $0.04 \%$ solution of methyl red were added to the 
culture in glucose phosphate broth which had been incubated at $30^{\circ} \mathrm{C}$ for five days. Red colour indicated positive test while yellow colour indicated negative test.

\section{Citrate utilization test}

Simmons Citrate medium was prepared, inoculated from a saline suspension of organism to be tested and incubated for $24 \mathrm{~h}$ at $37^{\circ} \mathrm{C}$. Growth in the medium with a change in colour from green to blue indicated a positive result.

\section{Carbohydrate fermentation test}

$10 \mathrm{ml}$ of carbohydrate fermentation broth was transferred in culture tubes along with the inverted Durham's tube and autoclaved at $121^{\circ} \mathrm{C}$ for 15 to $20 \mathrm{~min}$. The carbohydrate was prepared at $1 \%$ concentration in distilled water and autoclaved at $10 \mathrm{lbs} / \mathrm{inch}^{2}$. Separately, one loopful of organism from the culture plate was transferred in the tubes containing $10 \mathrm{ml}$ carbohydrate fermentation broth and $1 \mathrm{ml}$ of each sugar solution. A control was taken; tube that is not inoculated (without microorganism the tubes were incubated at $37^{\circ} \mathrm{C}$ for 24 to $48 \mathrm{~h}$ ). After incubation, the tubes were examined for acid production and gas production. Change in media colour from purple to yellow indicated the production of acid, which was a positive test. No colour change indicated negative test. Accumulation of gas bubbles in Durham's tube indicated the gas production and gave a positive test.

\section{Catalase test}

A loopful of culture was transferred from tube to a clean glass slide. Thereafter, a drop of hydrogen peroxide was added and mixed well. Evolution of bubbles indicated a positive test, whereas no evolution of bubbles indicated a negative test.

\section{Nitrate reduction}

Equal amount of $\alpha$ naphthol and sulphanilic acid were added to 24 to $48 \mathrm{~h}$ culture in nitrate reduction broth. The test tubes were examined for the appearance of red colour and gas bubbles. The occurrence of red colour and gas bubbles were presumptive for denitrification and indicated a positive test.

\section{Hugh and Liefson's test}

$2.3 \mathrm{ml}$ of $10 \%$ solution of glucose was added to Hugh and Liefson's oxidation and fermentation medium tubes and inoculated in duplicate and incubated aerobically at $37^{\circ} \mathrm{C}$ from 24 to $48 \mathrm{~h}$. Paraffin was spread over the media in one of the test tube after inoculation and then incubated to check for anaerobic bacteria. Positive tubes showed change in colour of the media green to yellow.

\section{Motility test}

The tube containing motility agar medium was stab inoculated. Positive test is indicated by the growth around the stab line that radiated outwards in all directions while no growth around stab line indicated negative test.

\section{Hydrogen sulphide test}

Tubes containing sulphide indole motility agar were stab inoculated and kept for incubation at $37^{\circ} \mathrm{C}$ for $24 \mathrm{~h}$. Blackening of the culture medium indicated a positive test.

\section{Antibiotic susceptibility pattern of $S$. aureus against selected antibiotics}

The test organism was tested for its sensitivity towards the given antibiotics using the Disk Diffusion Method (Bauer et al., 1966). Overnight, broth cultures were spread on the surface of Nutrient Agar Media plates with the help of sterile swabs. The antibiotic discs were placed on the agar surface and plates were incubated aerobically at $37^{\circ} \mathrm{C}$ for $24 \mathrm{~h}$. Zone of inhibition was measured in ' $\mathrm{mm}$ ' and the result interpreted on the basis of CLSI standards (Wayne, 2003).Antibiotic discs (Hi Media) which were used in the present study were Methicillin (M, $5 \mu \mathrm{g})$, Erythromycin $(\mathrm{E}, 15 \mu \mathrm{g})$, , Ciprofloxacin (Cf, $5 \mu \mathrm{g})$, Tetracycline $(\mathrm{T}, 30 \mu \mathrm{g})$, Kanamycin (K, 30 $\mu \mathrm{g})$, Gentamicin $(\mathrm{G}, 10 \mu \mathrm{g})$ Rifampicin (R, $30 \mu \mathrm{g})$, Linezolid (L, 30 $\mu \mathrm{g})$, Vancomycin $(\mathrm{Va}, 30 \mu \mathrm{g})$ and Tobramycin $(\mathrm{Tb}, 10 \mu \mathrm{g})$.

\section{Screening of LAB isolates for anti-MRSA activity}

The antibacterial activity was assayed against isolates of $S$. aureus using Agar Well Diffusion method (Schillinger and Lucke, 1989). The five strains of $S$. aureus were incubated in Nutrient Broth at $37^{\circ} \mathrm{C}$ for $24 \mathrm{~h}$. The broth culture was swab inoculated on Nutrient Agar. For the detection of antibacterial activity, the Lactobacilli strains were cultured in MRS broth, incubated anaerobically at $37^{\circ} \mathrm{C}$ for $36 \mathrm{~h}$. The broth culture of Lactobacilli was subjected to centrifugation at $5000 \mathrm{~g}$ for $15 \mathrm{~min}$. The supernatant was discarded and the pellet was washed twice with sterile normal saline. The washed pellet was then inoculated in Skim Milk Broth and incubated aerobically at $37^{\circ} \mathrm{C}$ for $36 \mathrm{~h}$. The inoculated Skim Milk Broth was subjected to centrifugation at $5000 \mathrm{~g}$ for $15 \mathrm{~min}$ and $20 \mu \mathrm{l}$ of the supernatant was filled on each $5 \mathrm{~mm}$ well on Nutrient Agar plates. Wells filled with sterile Nutrient Broth were included as control. Inhibition zones were measured after incubating the plates aerobically at $37^{\circ} \mathrm{C}$ for $24 \mathrm{~h}$ (Hassan et al., 2011). Inhibition was scored positive if the width of the clear zone around the well was observed.

\section{Statistical analysis}

The data was analyzed using Chi-square test, Z-test and two way classification of ANOVA.

\section{RESULTS AND DISCUSSION}

\section{Isolation and identification of lactobacilli from human faecal samples}

In the present investigation of the hundred human faecal samples collected from healthy adults, $23 \%$ were positive for Lactobacilli. On the basis of the biochemical characteristics of the 23 Lactobacilli isolates, it was observed that the three different Lactobacilli species isolated were L. plantarum, L. acidophilus and L. casei. Out of the 23 isolates, ten isolates were L. plantarum, eight were $L$. acidophilus and five were $L$. casei (Tables 1 and 2). On analyzing statistically, the data was nonsignificant at $0.05 \%$ probability. Study conducted by Dhewa and Goyal (2009) described incidence of LAB 
Table 1. Incidence and distribution of lactobacilli species in human faecal samples.

\begin{tabular}{ccccc}
\hline $\begin{array}{c}\text { Total number } \\
\text { of sample }\end{array}$ & $\begin{array}{c}\text { Total number of } \\
\text { Lactobacilli isolates (\%) }\end{array}$ & $\begin{array}{c}\text { Number of Lactobacillus } \\
\text { plantarum (\%) }\end{array}$ & $\begin{array}{c}\text { Number of Lactobacillus } \\
\text { acidophilus (\%) }\end{array}$ & $\begin{array}{c}\text { Number of } \\
\text { Lactobacillus casei (\%) }\end{array}$ \\
\hline 100 & 23 & $10(43.47)$ & $8(34.78)$ & $5(21.73)$ \\
\hline
\end{tabular}

$X^{2}=5.99$ (tabulated value), $X^{2}=24.32$ (calculated value), N.S=non-significant.

Table 2. Cultural, morphological and biochemical identification of lactobacilli Isolates.

\begin{tabular}{|c|c|c|c|c|}
\hline \multirow[b]{2}{*}{ Characteristic } & & \multicolumn{3}{|l|}{ Organism } \\
\hline & & $\begin{array}{l}\text { Lactobacillus } \\
\text { plantarum }\end{array}$ & $\begin{array}{l}\text { Lactobacillus } \\
\text { acidophilus }\end{array}$ & $\begin{array}{l}\text { Lactobacillus } \\
\text { casei }\end{array}$ \\
\hline \multirow{4}{*}{ Cultural characteristics } & Colour of colony & Cream & White & Off white \\
\hline & Shape of colony & Small, spherical & Small, spherical & Small, spherical \\
\hline & Elevation & Convex & Convex & Convex \\
\hline & Margin & Entire edges & Entire edges & Entire edges \\
\hline \multirow{4}{*}{$\begin{array}{l}\text { Morphological } \\
\text { characteristics }\end{array}$} & Gram's reaction & Gram positive & Gram positive & Gram positive \\
\hline & Arrangement of cells & $\begin{array}{l}\text { Long slender rods in } \\
\text { chains }\end{array}$ & $\begin{array}{l}\text { Rods in pairs and } \\
\text { chains }\end{array}$ & Small rods in chains \\
\hline & Spore formation & Non -sporing & Non -sporing & Non-sporing \\
\hline & Indole test & Negative & Negative & Negative \\
\hline \multirow{9}{*}{$\begin{array}{l}\text { Biochemical } \\
\text { characteristics }\end{array}$} & Methyl red test & Positive & Positive & Positive \\
\hline & Citrate test & Negative & Negative & Negative \\
\hline & catalase test & Negative & Negative & Negative \\
\hline & Motility test & Negative & Negative & Negative \\
\hline & Nitrate reduction test & Positive & Positive & Positive \\
\hline & $\mathrm{H}_{2} \mathrm{~S}$ production test & Negative & Negative & Negative \\
\hline & D-Glucose & $\mathrm{A}^{+} \mathrm{G}^{-}$ & $A^{+} G^{-}$ & $\mathrm{A}^{+} \mathrm{G}^{-}$ \\
\hline & D- Galactose & $\mathrm{A}^{+} \mathrm{G}^{-}$ & $\mathrm{A}^{+} \mathrm{G}^{-}$ & $\mathrm{A}^{+} \mathrm{G}^{-}$ \\
\hline & Sucrose & $\mathrm{A}^{+} \mathrm{G}^{-}$ & $A^{+} G^{-}$ & $\mathrm{A}^{+} \mathrm{G}^{-}$ \\
\hline \multirow{5}{*}{$\begin{array}{l}\text { Carbohydrate } \\
\text { fermentation }\end{array}$} & Maltose & $\mathrm{A}^{+} \mathrm{G}^{-}$ & $A^{+} G^{-}$ & $\mathrm{A}^{+} \mathrm{G}^{-}$ \\
\hline & Esculin & $\mathrm{A}^{+} \mathrm{G}^{-}$ & $A^{+} G^{-}$ & $W^{+} G^{-}$ \\
\hline & Fructose & $A^{+} G^{-}$ & $A^{+} G^{-}$ & $A^{+} G^{-}$ \\
\hline & D-Mannitol & $\mathrm{A}^{+} \mathrm{G}^{-}$ & $A^{-} G^{-}$ & $\mathrm{A}^{+} \mathrm{G}^{-}$ \\
\hline & Arabinose & $W A^{+} G^{-}$ & $\mathrm{A}^{-} \mathrm{G}^{-}$ & $\mathrm{A}^{+} \mathrm{G}^{-}$ \\
\hline
\end{tabular}

$A^{+}$, Acid positive; $A^{-}$, acid negative; $G^{+}$, gas positive; $G^{-}$, gas negative; $W A^{+}$, weakly positive.

from human faecal sample. Human intestinal mucous isolated from faeces of healthy Egyptian infants of 36 months of age were used as a substratum for the adhesion of probiotic Lactobacilli strains (Khalil et al., 2007). Lactobacillus acidophilus was the most frequently recovered species from infant faecal samples. This finding indicates that this species survived better in the gastrointestinal tract than the other strains (Khalil et al., 2007). Another study showed comparable results in which Lactobacilli were isolated from 50 faecal samples of 3 to 30-day old infants. The isolated Lactobacillus strains were further identified as $L$. acidophilus, Lactobacillus brevis, L. casei, L. plantarum, Lactobacillus fermentum, Lactobacillus reuteri and $L$. rhamnosus (Ozgun and Vural, 2011). Lactobacillus paracasei,
Lactobacillus gasseri, Lactobacillus delbrueckii, and Lactobacillus plantarum were isolated from faeces of healthy adults on MRS agar (Delgado et al., 2007).

\section{Antibiotic susceptibity pattern of $S$. aureus}

As a result of the antibiotic susceptibility test for the five strains of $S$. aureus, MCCB0065 was most resistant towards the ten antibiotics used, whereas MCCB0045 was most susceptible. Among the ten antibiotics, Tobramycin $(\mathrm{Tb})$ possessed least inhibitory potential whereas Erythromycin (E) had maximum inhibitory effect against the five strains of $S$. aureus. On the basis of resistance against Methicillin, three out of five $S$. aureus 
Table 3. Antibiotic susceptibility profile of Staphylococcus aureus strains.

\begin{tabular}{|c|c|c|c|c|c|c|c|c|c|c|}
\hline \multirow[b]{2}{*}{$\begin{array}{l}\text { S. aureus } \\
\text { strain }\end{array}$} & \multicolumn{10}{|c|}{ Antibiotic } \\
\hline & $\begin{array}{c}E \\
(15 \mu g)\end{array}$ & $\begin{array}{c}\text { Cf } \\
(5 \mu g) \\
\end{array}$ & $\begin{array}{c}T \\
(30 \mu g)\end{array}$ & $\begin{array}{c}K \\
(30 \mu g)\end{array}$ & $\begin{array}{c}G \\
(10 \mu g) \\
\end{array}$ & $\begin{array}{c}\mathbf{R} \\
(30 \mu g)\end{array}$ & $\begin{array}{c} \\
(30 \mu g)\end{array}$ & $\begin{array}{c}\text { Va } \\
(30 \mu g)\end{array}$ & $\begin{array}{c}\mathrm{Tb} \\
(10 \mu \mathrm{g})\end{array}$ & $\begin{array}{c}M \\
(5 \mu g) \\
\end{array}$ \\
\hline MCCB0045 & +++ & +++ & ++ & ++ & +++ & ++ & +++ & +++ & - & - \\
\hline MCCB0046 & ++ & ++ & - & ++ & ++ & ++ & +++ & ++ & ++ & - \\
\hline MCCB0065 & ++ & ++ & - & ++ & ++ & + & ++ & ++ & - & - \\
\hline MCCB0066 & ++ & ++ & - & ++ & ++ & +++ & - & ++ & ++ & ++ \\
\hline MCCB0067 & ++ & ++ & ++ & ++ & - & +++ & ++ & ++ & ++ & + \\
\hline
\end{tabular}

+++, Sensitive; ++, Intermediate; -, Resistant. E, Erythromycin; R, Rifampicin; Cf, Ciprofloxacin; G, Gentamicin; T, Tetracycline; L, Linezolid; K, Kanamycin; Va, Vancomycin; Tb, Tobramycin; M, Methicillin.

strains (MCCB0045, MCCB0046, and MCCB0065) were MRSA and the rest two strains (MCCB0066, MCCB0067) were MSSA. S. aureus strain MCCB0065 was multi-drug resistant as it was resistant to Tobramycin, Tetracycline and Methicillin (Table 3).

In a previous study, the antibiotic susceptibility of the MSSA and MRSA isolates was tested. The study conducted to test the antibiotic susceptibility pattern of Staphylococcus aureus strains showed that both MRSA and MSSA were susceptibility towards Gentamicin, Ciprofloxacin and Tetracycline (Sivakumari and Shanthi, 2009). This was comparable with the reports of other workers (Nwankwoet al., 2010; Khadri and Alzohairy, 2010).

\section{Antibacterial activity of Lactobacilli species against MRSA}

It was observed from the result of the antibacterial activity test of the three isolated strains of lactobacilli that $L$. casei showed maximum inhibition against МССВ0045, MCCB0065, MCCB0067 but showed moderate inhibition against MCCB0066 and minimum inhibition was seen against MCCB0046 (Figure 1). In L. plantarum, maximum inhibition was observed against MCCB0045, МСCB0067 whereas moderate inhibition was seen against MCCB0046, MCCB0065 and minimum inhibition was seen against MCCB0066. In L. acidophilus, maximum inhibition was observed against MCCB0067 whereas moderate inhibition was scored against MCCB0045, MCCB0065, MCCB066 and minimum inhibition was scored against MCCB0046. On the basis of the above observation, it was observed that $L$. casei had maximum inhibitory potential, showing maximum inhibition against three strains of $S$. aureus whereas $L$. acidophilus showed minimum inhibitory potential, as it showed maximum inhibition against one strain of $S$. aureus. On considering the resistance potential of the five pathogen strains of $S$. aureus towards the three isolated lactobacilli strains, it was observed that MCCB0067 was most resistant whereas MCСB0046 was most susceptible towards the three Lactobacilli strains. The range of the width of inhibition zones remained between 6.5 to $15.5 \mathrm{~mm}$ (Table 4).

On considering the three MRSA strains, MCCB0045 was most susceptible towards the three isolated Lactobacilli strains. MCCB0065 showed moderate susceptibility whereas MCCB0046 was least susceptible. On analyzing statistically, the data was significant due to Lactobacilli spp, at $5 \%$ probability and non-significant due to $S$. aureus strains at $5 \%$ probability. Studies have shown that $L$. acidophilus has the capacity to produce numerous metabolites that kill pathogenic bacteria (Oh et al., 2000). LAB were screened previously for anti-MRSA activity and $L$. fermentum was able to inhibit MRSA strains (Nawaz et al., 2008). Bactericidal proteins with antagonistic activities are produced by some strains of $L$. acidophilus. Among lactobacilli, strains belonging to species of the $L$. acidophilus and $L$. casei are frequently used as probiotic agents (Klaenhammer and Kullen, 1999). In a previous study, the isolated Lactobacillus strains exhibited the highest zone of inhibition $(15 \mathrm{~mm})$ against $S$. aureus (Arokiyamary and Sivakumar, 2011).

\section{Conclusion}

Out of a total of 100 faecal samples of healthy adults studied, 23\% were positive for Lactobacilli. The 23 Lactobacilli strains isolated from 100 human faecal samples in which $43.47 \%$ were L. plantarum, $34.78 \%$ were L. acidophilus and $21.73 \%$ were L. casei. Statistically, the differences were non-significant. $S$. aureus strains MCCB0045, MCCB0046, MCCB0065 were MRSA whereas MCCB0066, MCCB0067 were MSSA and strain MCCB0065 was multi-drug resistant. $L$. plantarum, L. acidophilus, and L. casei demonstrated antimicrobial potential to inhibit $S$. aureus including MRSA strains. L. casei showed maximum inhibitory potential. On analysing statistically the differences were significant. It is recommended that they may be considered beneficial, as compared to the regular antibiotics. Lactic acid bacteria will be ideal in producing 

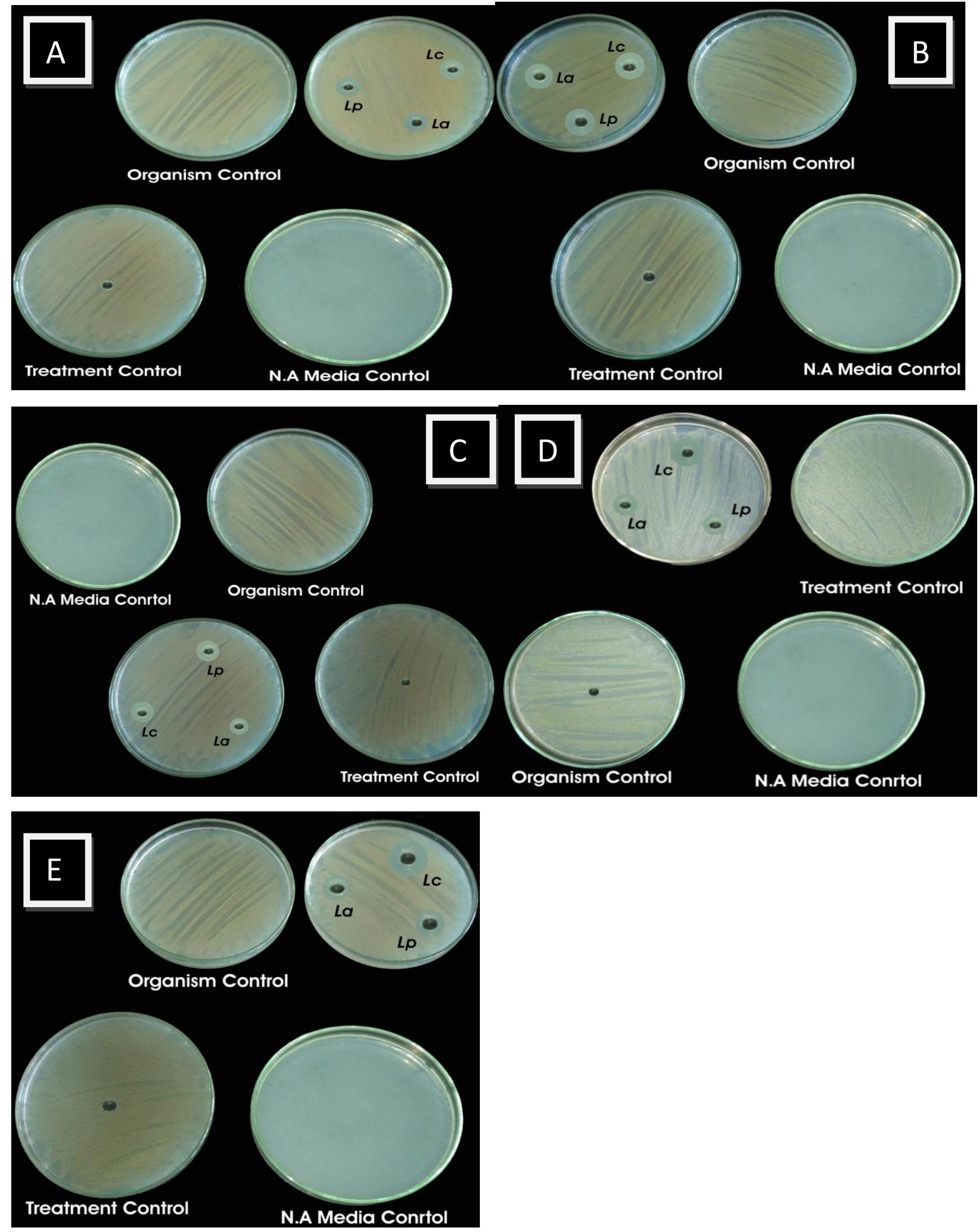

Figure 1. Antibacterial activity of lactobacilli strains against test pathogen Staphylococcus aureus. A, Staphylococcus aureus MCCB0045; B, S.aureus MCCB0046; C, Staphylococcus aureus MCCB0065; D, S. aureus MCCB0066; E, S. aureus MCCB0067; La, L. actobacillus acidophilus; Lc, L.actobacillus casei; Lp, Lactobacillus plantarum. 
Table 4. Antibacterial activity of lactobacilli strains against test pathogen Staphylococcus aureus.

\begin{tabular}{llccccc}
\hline \multirow{2}{*}{$\mathbf{S} / \mathbf{N}$} & \multirow{2}{*}{ Lactobacilli } & \multicolumn{5}{c}{ Zone of inhibition (mm) } \\
\cline { 2 - 6 } & MCCB0045 & MCCB0046 & MCCB0065 & MCCB0066 & MCCB0067 \\
\hline \multirow{2}{*}{2} & $\begin{array}{l}\text { Lactobacillus } \\
\text { plantarum }\end{array}$ & 15.00 & 10.50 & 11.00 & 6.00 & 15.50 \\
2 & $\begin{array}{l}\text { Lactobacillus } \\
\text { acidophilus }\end{array}$ & 11.50 & 7.00 & 12.00 & 11.50 & 14.50 \\
3 & $\begin{array}{l}\text { Lactobacillus } \\
\text { casei }\end{array}$ & 15.50 & 6.00 & 13.00 & 8.00 & 14.00 \\
\hline
\end{tabular}

Due to lactobacilli: $\mathrm{F}(\mathrm{Cal})=5.98 ; \mathrm{F}(\mathrm{Tab})=3.84 ; \mathrm{C}$.D at $5 \%=3.044 ;$ Result=S (significant). Due to Staphylococcus aureus: $\mathrm{F}$ (Cal) $=0.03 ; \mathrm{F}(\mathrm{Tab})=.4 .46 ; \mathrm{C} . \mathrm{D}$ at $5 \%=3.044$.

antimicrobial compounds effective against MRSA. The Lactobacilli strains isolated in the present study demonstrated anti-methicillin resistant Staphylococcus aureus activity. The isolated strains of $L$. plantarum, $L$. acidophilus, and $L$. casei can also be used as probiotic (after the positive reports of in vivo experimentations). This strategy should be applied for the control of reemerging MRSA infections.

\section{REFERENCES}

Arokiyamary A,Sivakumar PK(2011).Antibacterial activity of Bacterocin producing Lactobacillusspecies isolated from traditional milk products. Curr. Bot. 2:5-8.

Bauer AW, Kirby WMM, Sherris JC, Truck M(1966). Antibiotic susceptibility testing by a standardized single disk diffusion method. Ame. J. Clin. Pathol. 45:365-378.

Cespedes C, Salim B, Miller M, Lo SH, Kreiswirth BN, Gordon RJ, De Man JD, Rogosa M, Sharpe ME(1960).A medium for the cultivation of Lactobacilli. J. Appl. Bact. 23:130-135.

Delgado S, Suarez A, Mayo B(2007). Dominant cultivable Lactobacillus speciesfrom the feces of healthy adultsin northern Spain. J. Int. Microbiol. 10:141-145.

Dhewa T, Goyal N(2009). Effect of inulin, honey and gum acacia on growth of human faecal potential probiotic Lactobacilli. J. Life Sci. 3:29-34.

Griethuysen AV, Pauw M, Leeuwen NV, Heck M, Willemse P, Buiting A, Kluytmans J (1999). Rapid slide agglutination test for detection of methicillin resistance in Staphylococcus aureus. J. Clin. Microbiol. 37:2789-2792.

Hartnett DJ, Vaughan AM, Sinderen D(2002). Antimicrobial- producing lactic acid bacterial isolates from raw barley and sorghum. F. Instn Brew. 108:169-177.

Hassan PA, PehK, Liong M(2011). Antimicrobial activity of metabolites of various strains of Lactobacillus acidophilus. International Scientific Conference 2011. 42366:4-9.

Khadri H, Alzohairy M (2010). Prevalence and antibiotic susceptibility pattern of methicillin-resistant and coagulase-negative Staphylococci in a tertiary care hospital in India. Intern. J. Med. Sci. 2:116-120.

Khalil R, Mahrous H, Halafawy KE, Kamaly K, Frank J, Soda ME(2007). Evaluation of the probiotic potential of lactic acid bacteria isolated from faeces of breast-fed infants in Egypt.Afr. J. Biotechnol. 6: 939949.

Klaenhammer TR, Kullen MJ (1999). Selection and design of probiotics. Int. J. Food Microbiol. 50:45-57.
Lowly FD (1998).Staphylococcus aureus. Infect. N. Engl. J. Med. 339:520-532.

Nawaz SK, Riaz S, Riaz S, Hasnain S(2008).Screening of anti- MRSA bacteriocins producing bacteria. Afr. J. Biotech. 8:365-368.

Nwankwo E, Abdulhadi S, Magagi A, Ihesiulor G (2010). Methicillin resistant $S$. aureus (MRSA) and their antibiotic sensitivity pattern in Kano, Nigeria. Afr. J. Cln. Exper. Microbiol. 11:129-136.

Oh S, Kim SH, Worobo RW(2000). Characterization and purification of a bacteriocin produced by a potential probiotic culture, Lactobacillus acidophilus. J. Dairy. Sci. 83:2747-2752.

Ozgun D, Vural HC (2011). Identification of Lactobacillus strains from faecal specimens of babies and human milk colostrums by API 50 CHL system. J. Med. Gen. Genom. 3:46-49.

Petrova M, Georgieva R, Dojchinovska L, Kirilov N, lliev I, Antonova S, Schillinger U, Lucke KF(1989).Antibacterial activity of Lactobacillus sake from meat. Appl. Environ. Microbiol. 55:1901-1906.

Sivakumari V, Shanti G (2009).Antibiotic susceptibility of common bacterial pathogens isolated from diabetic pus. Res. Adv. Biotech. 1:10-13.

Verdenelli MC, Ghelfi F, Silvi S, Orpianesi C, Cecchini C, Cresci A (2009). Probiotic properties of Lactobacillus rhamnosus and Lactobacillus paracasei isolated from human faeces. Eur. J. Nutr. 10: 1007.

Vesterlund S, Karp M, Salminen S, Ouwehand AC(2006).Staphylococcus aureusadheres to human intestinal mucus but can be displaced by certain lactic acid bacteria. J. Microbiol Methods 152:1819-1826.

Voravuthikunchai SP, Bilasoi S, Supamala O (2006). Antagonistic activity against pathogenic bacteria by human vaginal lactobacilli. Anaerobe. 12:221-226.

Wayne PA (2003). Performance standards for antimicrobial susceptibility testing, fifteenth informational supplement, CLSI document. 26:1-3. 